\title{
Brown University Library meets the preservation challenge
}

\author{
A challenge grant leads to a preservation endowment
}

\author{
by Eric C. Shoaf
}

$\mathrm{L}$ ibraries are finding it harder to budget for preservation of their collections. The impact of ever-rising serials costs, electronic products and other new media, as well as continued demand for print have left library administrators strapped for funds to operate traditional, but still necessary, preservation programs

Many of these programs began in the 1970 s and 1980s when grant-funded microfilm projects were a main source of funds for reformatting brittle collections. Most libraries carved funds for their preservation departments out of acquisitions budgets as well, and many continued to receive soft money for project-based preservation treatment programs into the early $1990 \mathrm{~s}$

But much of that money is gone now, because of cutbacks in federal funding through the National Endowment for the Humanities (NEH), and because the funding models for microfilm were not transferable to projects for which digital archiving was the primary preservation tool.

Lack of consistent standards for image capture, storage, retrieval, search engines, and data refreshment made it difficult for libraries to use the digital model as a main preservation feature.

\section{The NEH Challenge Grant}

Now, as every area of library expenditure comes under scrutiny, preservation department managers are scrambling to find new sources of external funding.

At Brown University, we have a long tradition in preservation but we were feeling the funding pinch as microfilm projects wound down and other library expenditures began to crowd the annual budget. In thinking about funding for preservation, it was decided early on to create an endowment for preservation activities rather than to create another multi-year project that would inevitably end.

It was also decided not to apply to the NEH Preservation and Access program but to seek funding from NEH's Challenge Grant arm. A challenge grant is one where funds are raised by the institution and matched by NEH at either a 3:1 or 4:1 rate.

To our knowledge, at that time no other institution sought funding for preservation activities from the Challenge Grant program. Therefore, we felt the need to propose a new approach to preservation of

\section{About the author}


research collections, both to get the attention of NEH and also the attention of individuals and businesses who would be interested in contributing to such an endeavor.

\section{Creating the proposal}

In 1995, a series of cliscussions was held among library staff from Preservation, Special Collections, and Technical Services to find a key idea for the proposal. We looked at what Brown had done for library preservation and what we were currently doing. We looked at how other libraries structured their preservation programs. What we saw was much similarity, and differences only in degree.

Out of these discussions an idea emerged that was deceptively simple, yet surprisingly untested. Brown makes treating existing collections a priority for preservation, as most other research libraries do. But we identified new acquisitions as a group of materials that seldom receives preservation attention

Traditional preservation models assume new acquisitions to be ready for use and basically sound in terms of paper quality, bindings, and relative permanence of content. But our test surveys of new acquisitions revealed that as many as $20 \%$ of newly acquired books were printed on acidic paper. Further, the percentage of gift collections processed into library holdings at Brown was higher than expected. These gift books are added to the collection in "used" condition and often need substantial care

We proposed a new model for providing preservation treatments at Brown and created a dual action plan with these components:

a) Surveying and treating important $\mathrm{Hu}$ manities collections already owned by the library. These account for nearly 1 million items including a wide array of formats, such as monographs, journals, broadsides, manuscripts, sheet music, sound recordings, and leaflets. This is the traditional preservation component.

b) Surveying and treating all new acquisitions for the Humanities collections, which amount to more than 4,500 items annually. Each new purchase or gift in these subject areas is scrutinized, tested, and treated as necessary. In this way, preservation of newly acquired research materials is simultaneous with retrospective preservation work on collections already owned by the library.

This formed the basis of Brown's new approach to preservation of library materials: to survey and treat all new acquisitions for preservation needs, and to survey and treat existing collections as we are able over time.

\section{Treatments proposed}

Another important feature of Brown's proposal is a provision for full use of advanced preservation treatments, such as digitizing and paper deacidification, and also for the future use of preservation technologies not yet fully developed. We were careful to insert language into the proposal to allow for uses of new preservation technologies, since the endowment will fund preservation activities in perpetuity.

In addition, the Brown plan focuses on all formats in Humanities subject areas. Not only will books and other paper-based materials receive treatment, but also recordings on audiotape, vinyl, compact disk, videotape, and computer disks. The treatments we proposed to perform in our dual action plan:

1 Deacidification. Brown has been working with Preservation Tech nologies Inc. of Pittsburgh, Pennsylvania, which developed the Bookkeeper paper deacidification system. Recent condition surveys have indicated that nearly $50 \%$ of Brown's paper-based collections are printed on acidic paper, but are not yet brittle.

This figure is similar to that obtained from surveys at other research libraries and represents materials for which an intervening process, such as deacidification, can greatly lengthen useful life and accessibility to scholars. New print acquisitions were also surveyed and some $20 \%$ were found to have acidic paper that was not yet brittle.

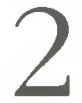

Repair of collections. The Brown Library has extensive book and paper treatment facilities, including a conservation lab, fine binding studio, and repair unit. Staff expertise has been devel- 
oped following years of training and handson experience. As part of the intensive testing and selection procedure, both materials in existing collections and newly acquired items needing repair will receive any conservation procedures deemed necessary.

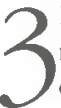
Re-housing. Much of the nonbook material is poorly stored and in need of re-housing. Maps, broadsides, manuscripts, sound recordings, and motion pictures are all represented within $\mathrm{Hu}-$ manities collections. Our surveys show that more than $50 \%$ are improperly housed and in need of attention. Archival quality boxes and other materials are being used and treatments to flatten, dismount, clean, and protect the materials are expanding.

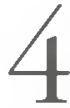

Reformatting. For the last 15 years nearly 20,000 volumes from Brown Library collections have been reformatted through microfilming. Brown has more recently been investigating digital imaging technology as a preservation tool and expects a hybrid system of digital access/microfilm surrogate to shortly be come the standard in this area.

A significant number of Humanities collection volumes were printed on paper that has become brittle and is in need of reformatting. Surveys conducted in 1992 show that as much as $15 \%$ of the collection is already brittle and at risk of loss. A significant number of the items that form Brown's core humanities collections have inherent artifactual value that must be maintained. Providing surrogates for content and use provides a means to keep original materials protected for future generations of scholars

As part of the intensive testing and selection procedure, items needing reformatting are being microfilmed or photocopied onto acid-free paper. Brown hopes to begin using digital storage and retrieval systems and other new preservation technologies as they are developed. The Brown Library is committed to leadership in using new technologies as they are adapted for both librarianship and scholarly communication.

Staffing. Two additional permanent staff will be hired and will conduct surveys of existing collections (which account for some 1 million individual items in humanities collections) to identify those in need of conservation, make decisions for treatment options, oversee repair, rehousing, reformatting, and other treatments as necessary, and to coordinate record keeping and statistics. Newly acquired materials will also be surveyed and those in need of preservation treated soon after cataloging.

\section{A little help from the Development Office}

Once library staff developed the preservation idea and plan, we went to the university's Development Office for fundraising guidance. The library had successfully completed fundraising for two previous challenge grants and we were confident that a third was achievable. However, it was important to consult with Development Office staff, since they would be doing the bulk of the fundraising work.

They accepted the challenge and assisted with writing parts of the grant proposal. The proposal was completed in April 1996 following the printed guidelines provided by the NEH Challenge Grant program.

In December 1996, we received word that Brown's proposal had been funded for $\$ 625,000$. With Brown's portion of the match, the Challenge Grant would create a $\$ 3.2$ million endowment for preserving library materials in the humanities. The fundraising period was four years. But due to excellent planning and hard work by the Development Office, Brown raised donations totaling $\$ 2.5$ million for the preservation endowment in only three years, which completed the Challenge Grant match.

With the endowment established, the library began receiving income for preservation treatments in 1999 and the first of two new permanent staff members was hired early in 2000

We feel that Brown's new approach can serve as a model for preservation programs at other major research institutions and we expect to report on progress implementing the dual action preservation plan in the professional library literature as our experience grows. 

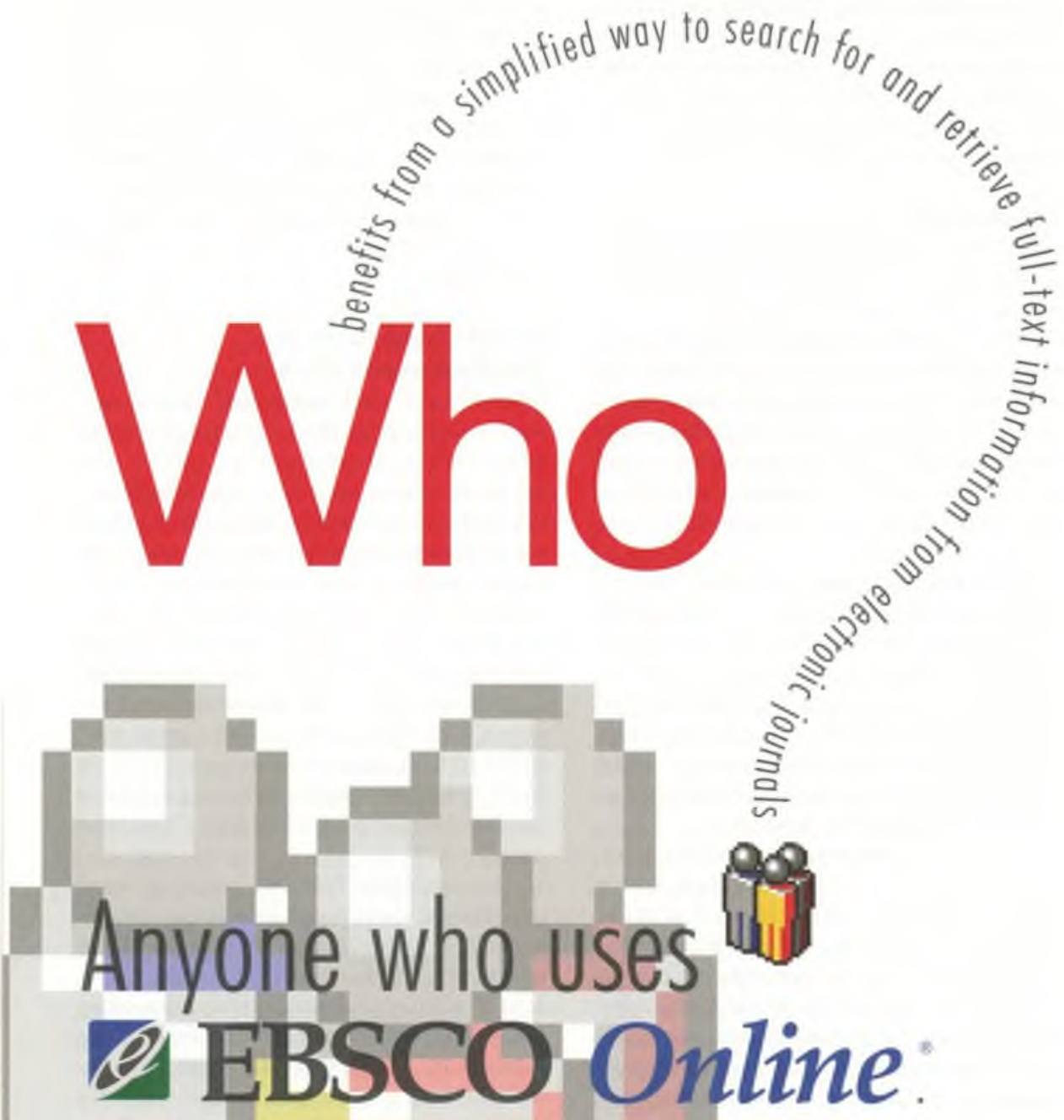

- Anyone who needs a quick, comprehansive look at the latest research in their field (via full text delivery).

- Anyone who manages a large volume of information for their company or library.

- Anyone who doesn't want to waste their time searching through electronic journals one-by-one.

For more information: go to www.ebsco.com and select "Electronic Journals." 